\title{
Tomás Pérez Vejo: Elegía criolla. Una reinterpretación de las guerras de la independencia hispanoamericanas. Ciudad de México: Crítica, 2019, 265 pp.
}

\section{Leopoldo José Prieto López ${ }^{1}$ \\ Universidad Francisco de Vitoria (España)}

No es necesario recurrir a Heidegger o a sus discípulos para saber que una cosa es la historia como hechos acontecidos en el pasado y otra bien distinta es la historia como narración de los mismos. Lo primero es conocido por los alemanes como Geschichte (de geschehen, ocurrir, acontecer). Lo segundo es designado en aquella lengua con el término Historie en el sentido de historiografía. Desde luego la historia acontecida es el criterio radical de verdad que debe guiar la narración historiográfica. Un sano criticismo y antidogmatismo histórico, como creemos pone en práctica Tomás Pérez Vejo en este libro, nos debe hacer recelar de grandes síntesis no suficientemente atentas a los hechos acontecidos (y el autor de este libro los presenta en abundancia) y no raramente presentados o re-presentados (es decir, literalmente imaginados ${ }^{2}$ ) al calor de los propios intereses de una parte implicada en la contienda ideológica o incluso bélica. En tales circunstancias la narración histórica degenera en exaltada lírica nacionalista o, desde otro punto de vista, en propaganda ideológica.

En tal sentido, Pérez Vejo nos propone en el Epílogo de su libro un ejemplo de contraste no infrecuente en los casos de las independencias hispanoamericanas entre los hechos acontecidos y la narración historiográfica (o como ahora se dice, el relato) de los mismos. He aquí el contraste: "En la Plaza Grande de Quito un monumento recuerda el Primer Grito de Independencia Hispanoamericana que dio origen a la Junta Provisional de agosto de 1809. En la base, el león español, herido, con una punta de lanza en su costado, se aleja tambaleante entre los despojos de la vieja monarquía, armas, pendones y una gran cruz virreinal. En una de las esquinas el cóndor ecuatoriano remonta majestuoso el vuelo con las cadenas de la opresión española a sus pies. Una bella metáfora en bronce de lo que habría sido la primera declaración de la independencia en la América española" (p. 236).

\footnotetext{
${ }^{1}$ https://orcid.org/0000-0002-0990-6445

${ }^{2}$ Los clásicos entendían que la imaginación, como una de las facultades sensoriales internas, era la capacidad de re-presentar un objeto en ausencia del mismo. De donde la libertad de la imaginación, pero también la posibilidad de falsificación de los datos reales.
} 
Pero atengámonos a la historia acontecida: "El problema es que el Acta de Independencia firmada por la Junta a la que el monumento rinde homenaje dice cosas tan extrañas como que su presidente «prestará juramento solemne de obediencia y fidelidad al rey en la catedral inmediatamente y lo hará prestar a todos los cuerpos constituidos, así eclesiásticos como seculares. Sostendrá la pureza de la religión, los derechos del rey y los de la patria y hará guerra mortal a todos sus enemigos, principalmente franceses, valiéndose de cuantos medios y arbitrios honestos le sugiriesen el valor y la prudencia para lograr el triunfo» o que la Junta «gobernará interinamente a nombre y como representante de nuestro legítimo soberano, el señor don Fernando Séptimo y mientras su majestad recupere la península o viniere a imperar en América»” (pp. 236237). Atendiendo al tenor literal del Acta de independencia apostilla Pérez Vejo con ironía: "Es posible que sea una proclamación de independencia, pero suena rara" (p. 237). Permítasenos proseguir con la cita: "La historiografía patriótica ecuatoriana redondea el relato en bronce con una emotiva narración en la que las tropas españolas truncan esta primera alba de la «libertad» americana con el asesinato de la mayoría de los miembros de la Junta en una orgía de saqueos, robos, sangre y destrucción. Lo que no dice es que el núcleo principal de estas «tropas españolas» eran las milicias de pardos de Lima, zambos americanos, al menos tan americanos como los criollos a los que asesinaron y las damas quiteñas a las que violaron". Así las cosas, "un monumento con dos cóndores desgarrándose las entrañas habría sido, quizás, una metáfora bastante más precisa de lo ocurrido que la profecía de pasado en bronce imaginada para la conmemoración del «Primer Centenario de la Independencia»" (p. 237). "Dos cóndores desgarrándose las entrañas": he aquí, pues, la tesis central del libro, a saber: que aquellas guerras presentadas historiográficamente como guerras de independencia entre españoles contra americanos no fueron en realidad sino guerras civiles de americanos (criollos y no criollos) contra americanos. Más en concreto, guerras civiles surgidas de la necesidad de determinar cuál habría de ser el nuevo sujeto de la soberanía política tras el colapso de la Monarquía hispánica.

La tesis es avalada por el hecho de que "el número de peninsulares era prácticamente despreciable, siendo probable que en ninguno de los diferentes virreinos llegase ni siquiera al 1\% de la población total y que, como consecuencia, los ejércitos de ambos bandos estuvieran formados básicamente por americanos (criollos, indios y castas)" (p. 44).

Siendo esta la tesis, Pérez Vejo pone de manifiesto desde el principio que el propósito de este libro es aventurar una nueva interpretación general de las guerras de independencia, proponiendo para ello "una relectura de eso que hemos denominado guerras de independencia desde una mirada que intente evitar lo que hay de construcción posterior, que intente analizar y resolver 
problemas y no darlos por previamente analizados y resueltos" (p. 31). De esta nueva interpretación general cree el autor del libro que se obtienen dos ganancias teoréticas. No solo la posibilidad de repensar lo ocurrido entre 1810 y 1821 como guerras civiles y no como guerras de independencia, lo cual abre la perspectiva de una nueva mirada sobre el pasado, a la vez que sobre el presente y el futuro, de las naciones hispanoamericanas surgidas de aquella colosal crisis. También se nos ofrece así la posibilidad de "explicar por qué las distintas historiografías nacionales, las americanas pero también las europeas, han preferido entender los conflictos ocurridos en la transición del Antiguo Régimen a la sociedad liberal como guerras de independencia o como revoluciones, pero no como guerras civiles" (p. 48). Naturalmente estas afirmaciones sobre el carácter de guerra civil de aquellas contiendas, como también las razones de la historiografía para eludirlo, deben ser debidamente presentadas y justificadas, como hace el autor a lo largo del libro, creemos que con fortuna.

$* * *$

Quien escribe estas líneas lo hace con temor y temblor. Él mismo no es competente en un sentido propio en el campo de la historia. Es historiador, pero de la filosofía, o en un sentido más modesto, historiador del pensamiento. Ahora bien, utilizando una precisión terminológica de aquellos viejos escolásticos que de lógica eran verdaderos maestros, la historia del pensamiento es materialmente un saber histórico (y en ello se ampara para escribir estas líneas sobre un libro de historia), pero formalmente es un saber filosófico. Al historiador de la filosofía, que esencialmente hablando es un filósofo, interesan no tanto las reconstrucciones históricas sobre los hechos, sino los conceptos mismos, los principios, las ideas, las teorías, etc. empleadas para ello. Por otro lado, este reseñador ni siquiera como historiador del pensamiento se ha ocupado largamente de las ideas que alimentaron aquellos procesos de emancipación o independencia. Únicamente lo ha hecho en un reciente trabajo en cuya preparación ha tenido ocasión de descubrir, para su sorpresa, que buena parte de las grandes ideas políticas presentes en aquellas Juntas hispanoamericanas $\mathrm{y}$ en aquellos manifiestos y declaraciones de los Cabildos americanos de inicios del siglo XIX no son tanto las ideas ilustradas procedentes de Locke, Montesquieu o Rousseau, sino sobre todo aquellas otras que hace años ya Alfonso García Gallo llamó el pactismo hispánico ${ }^{3}$. Por pactismo hispánico entendía García Gallo el conjunto de ideas políticas procedente de la tradición medieval española, codificado en términos de teoría ética y política por algunos

${ }^{3}$ Cf. A. García Gallo, Manual de Historia del Derecho español, vol. I. Madrid. Artes Gráficas y ediciones, 1979, pp. 745-754

Araucaria. Revista Iberoamericana de Filosofia, Política, Humanidades y Relaciones Internacionales, año 22, $\mathrm{n}^{\circ} 44$. Segundo semestre de 2020. Pp. 595-604. ISSN 1575-6823 e-ISSN 2340-2199 https://dx.doi.org/10.12795/araucaria.2020.i44.28 
autores españoles de los siglos XVI y XVII. Insistamos en que los principios del pactismo hispánico son de origen medieval, aunque su mejor elaboración lógica y su justificación ético-política y teológica es debida a autores como Suárez, Molina, Mariana, Vitoria (y otros muchos autores). Aquellos principios pactistas eran en lo fundamental cuatro: a) la titularidad del poder político pertenece, en última instancia, al pueblo (soberanía popular); b) este, por medio de sus delegados y representantes, puede transferir el uso de dicho poder (no su propiedad) al rey; c) en consecuencia, el pueblo conserva o retiene la titularidad radical (in habitu) del poder político; d) por lo cual, sobrevenidas circunstancias de especial gravedad y, sobre todo, ante un grave incumplimiento del rey de sus obligaciones pactadas con el pueblo, el poder político soberano retorna o revierte al pueblo ${ }^{4}$.

Ahora bien, en la grave y excepcional crisis política de 1808, ante la flagrante vulneración del orden político-constitucional vigente (como, en efecto, era la abdicación del monarca y la transmisión del poder a un monarca extranjero al margen de las leyes sucesorias del Estado y sin el consentimiento del pueblo expresado en las Cortes), que tenía como consecuencia la extinción del pacto de transferencia del poder al rey, el poder político soberano debía entenderse retornado al pueblo, el cual a partir de entonces pasaba a ser titular in actu de dicho poder soberano. Es el fundamental principio de la reversión o reasunción de la soberanía por parte del pueblo, invocado por la práctica totalidad de Juntas españolas e hispanoamericanas en la crítica coyuntura de los años 1808 y siguientes, es decir, en los momentos de la cautividad de la familia real española, la abdicación de Carlos IV y Fernando VII en favor de Napoleón sin consulta del pueblo y la invasión del territorio peninsular por las tropas francesas. Ahora bien, en aquellos manifiestos y declaraciones de Juntas y Cabildos no se proclamaba la independencia de España, sino, justamente, al contrario: la reafirmación de lealtad al rey de España secuestrado, el rechazo del invasor francés y la manifestación de inequívoca pertenencia a la monarquía hispánica.

En breve, este estudio sobre el pactismo hispánico, desde un punto de vista muy distinto al del libro que reseñamos, corrobora no pocas afirmaciones de este, no tanto en lo que respecta a las ideas de los procesos de emancipación hispanoamericanos, de lo que Pérez Vejo no trata, sino sobre el carácter de contienda civil posterior a aquella profunda crisis de soberanía política, en ausencia del rey legítimo, invadido el territorio y usurpado el trono. Desde luego, la convergencia de resultados a partir de presupuestos distintos es un indicio de validez (por no decir, de verdad) de una teoría ${ }^{5}$, como en este

${ }^{4}$ L. Prieto López, "Francisco Suárez, el pactismo hispánico y la emancipación de la América española", en F. Castilla Urbano (ed,), Civilización y dominio. La mirada sobre el otro, Ediciones Universidad de Alcalá de Henares, Alcalá de Henares 2019, 201-226.

${ }^{5}$ William Whewell, un filósofo británico de la ciencia del s. XIX, emplea en su Filosofia de las 
caso es la teoría de Pérez Vejo sobre unas guerras que no eran, en realidad, de independencia, sino guerras civiles posteriores al colapso de la Monarquía hispánica y la lógica reasunción de la soberanía por las Juntas y Cabildos.

$* * *$

El libro que presentamos consta de ocho partes: introducción (“¿Por qué volver sobre las guerras de independencia?", pp. 9-52), capítulo primero ("Las palabras como armas: revolución, guerra de independencia o guerra civil”, pp. 53-96), capítulo segundo ("Unas guerras de liberación nacional sin naciones", pp. 97-138), capítulo tercero ("Criollos contra peninsulares: la bella leyenda", pp. 139-176), capítulo cuarto ("De la revolución de la Independencia a las revoluciones de las independencias”, pp. 177-222), epílogo (pp. 223-238), bibliografía (pp. 239-250), índice onomástico (pp. 251-254).

Consideramos centrales la introducción y el capítulo primero. La introducción, en efecto, contiene la justificación de la reinterpretación sostenida por el autor de los procesos emancipadores como guerras civiles. El capítulo primero es, a su vez, la exposición detallada de la tesis central del libro. A ellos nos limitaremos ahora, dada la necesaria concisión de una reseña.

$* * *$

Veamos las ideas principales de la introducción. La historiografía liberal ha presentado reiteradamente las "guerras de la independencia contra España" como "la liberación de los pueblos sometidos de la opresión de los conquistadores llegados del otro lado del Atlántico, el fin de un desgraciado paréntesis de trescientos años" (p. 11). La cuestión, naturalmente, es si este relato historiográfico hace justicia a los hechos; o, con los términos alemanes antes aludidos, si esta Historie es fiel a los hechos de la Gechichte hispanoamericana acaecidos al alba del siglo XIX. Se pregunta por eso Pérez Vejo: “¿Pasaron las cosas así? ¿Fueron las guerras de independencia guerras de liberación nacional? ¿Hubo realmente guerras de independencia en América o solo la disgregación de un viejo orden imperial?" (p. 12). Según el autor, los hechos parecen confirmar el segundo miembro de esta última alternativa. En efecto, "la antigua unidad política de la Monarquía católica, una de las grandes protagonistas de la historia de los últimos tres siglos anteriores, había dejado su lugar a poco menos de veinte estados, todos ellos, incluida España, de manifiesta irrelevancia internacional" (p. 13). Una precisión conceptual

ciencias inductivas (1840) el término inglés consilience para expresar la convergencia o acuerdo de resultados obtenidos en los diversos campos de la experimentación como medio de demostración de una teoría.

Araucaria. Revista Iberoamericana de Filosofía, Política, Humanidades y Relaciones Internacionales, año 22, $\mathrm{n}^{\circ} 44$. Segundo semestre de 2020. Pp. 595-604. ISSN 1575-6823 e-ISSN 2340-2199 https://dx.doi.org/10.12795/araucaria.2020.i44.28 
se impone: ¿qué es la Monarquía católica? Según Pérez Vejo, "la definición jurídica más precisa sería la de monarquía compuesta, un conglomerado de reinos, provincias y señoríos unidos por la común fidelidad al monarca. No estamos hablando de una nación española dueña de un imperio, sino de una realidad política diferente, anacional en sentido estricto, con lógicas de funcionamiento ajenas a lo nacional" (pp. 15-16). De hecho, "en la Monarquía católica el hecho nacional era completamente irrelevante y la acción política pasaba por ser súbdito de un monarca, no miembro de una nación" (p. 16).

El relato canónico afirma que aquellas guerras fueron "unas guerras de liberación nacional en las que las naciones americanas, esclavizadas por la nación española, consiguieron su independencia, poniendo fin a tres siglos de colonialismo y explotación económica" (p. 17). Su "núcleo duro" es "la existencia previa de identidades nacionales en el interior de la Monarquía católica y, como consecuencia, la interpretación de las guerras de independencia como un conflicto de naciones en lucha por su soberanía, al que se le suele añadir en flagrante contradicción, un conflicto entre criollos y peninsulares" ( $p$. 17). François-Xavier Guerra llama a este relato canónico "las interpretaciones clásicas de las independencias" (p. 18). Pérez Vejo se suma a esta escuela decididamente, pues tal relato no es sino "una bella leyenda que tiene en su contra casi todo, salvo la vacua satisfacción de lo políticamente correcto [...] una magnífica forma de no entender nada" (p. 18). Pero ¿por qué una bella leyenda? Por cuatro razones. Primero, "porque no existían naciones, en el sentido moderno del término, en el momento del estallido de las guerras de la independencia. Las naciones no fueron la causa de las guerras de independencia, sino su consecuencia. En el origen de estas no hay un problema nacional, de naciones en conflicto, sino un conflicto de soberanía sobre quién tenía derecho a gobernar en ausencia del monarca" (p. 18). Segundo, "porque hablar de sistema colonial en una monarquía del Antiguo Régimen [...] resulta problemático". Tercero, "porque efectivamente las guerras de independencia fueron una gesta criolla, pero no porque se enfrentaran criollos contra peninsulares, sino porque fue una lucha de criollos contra criollos. El papel decisivo, tanto del lado insurgente como del realista, lo tuvieron los españoles americanos, no los europeos. La imagen de un enfrentamiento criollos/peninsulares como eje del conflicto es el resultado de la propia propaganda insurgente, que la utilizó como elemento de movilización política, y de la historiografía del siglo XIX" (p. 19). Cuarto, "porque no siempre la reacción y las clases altas estuvieron del lado de los realistas, y el liberalismo y las clases bajas de los insurgentes. Esto es también una construcción historiográfica posterior que buscó ubicar el conflicto en un enfrentamiento entre progreso y reacción" (p. 20).

En breve, "las contradicciones que resultan de este relato historiográfico son tan flagrantes que, en medio de las conmemoraciones de los doscientos 
años de aquellos hechos, no solo parecía pertinente volver, una vez más, sobre lo sucedido en las primeras décadas del siglo XIX sino, incluso, preguntarse si hubo alguna vez unas guerras de independencia en los territorios americanos de la Monarquía católica” (p. 20). Solo en la década de los años ochenta del pasado siglo ha empezado a imponerse una posición revisionista de las independencias, con François-Xavier Guerra y Jaime E. Rodríguez a la cabeza. Las guerras de independencia fueron un conflicto político, de lucha por la legitimidad del poder. En su origen "hay un problema político, pero no [...] de identidades en conflicto, sino un conflicto de soberanías" (p. 31). El punto de partida fue el año 1808, cuando el rey ausente del país, abdica de su cargo y lo transfiere a un rey extranjero, invasor de su territorio (cf. p. 34). Ahora bien, tal abdicación era nula de pleno derecho sin el consentimiento del pueblo expresado por las Cortes. El poder transferido por el pueblo al rey no era de libre disposición para este. La ilegítima abdicación a favor de Napoleón lo hacía retornar en realidad a su legítimo titular radical: el pueblo. Es la tesis que hemos mencionado antes con el nombre de retorno o reversión de la soberanía al pueblo. La consecuencia de aquellos momentos de crisis fue "el sentimiento de vacío de poder y de legitimidad generalizado". "Se tuvo que hacer frente a la vez a la ausencia del monarca y al desconocimiento de las instituciones de gobierno que legítimamente lo representaban [...] En realidad, el descabezamiento de la estructura institucional de la Monarquía católica fue absoluto, la perplejidad de las élites políticas también" (p. 35). Al vacío de poder, colmado inicialmente por las Juntas, sigue luego "la búsqueda de soberanías alternativas", que desembocó de manera muy rápida, "en la aparición de la nación como sujeto alternativo, y muy pronto único imaginable, de soberanía” (p. 36).

$* * *$

El capítulo primero aborda la cuestión central del trabajo: la reinterpretación como guerras civiles de las habitualmente consideradas guerras de independencia. Desde luego hay que preguntarse por qué la historiografía decimonónica habría negado, o disimulado al menos, el carácter de contiendas civiles de aquellas guerras. La razón parece radicar en que el término de guerra civil es un tabú en la mayor parte de las historiografías nacionales, "que tienden a ennoblecer el pasado borrando cualquier alusión al fratricidio [...] La solución es reescribir la historia [...] Convertir al enemigo en extranjero y a la guerra civil en guerra de independencia cumple de manera perfecta esta doble función de deslegitimación/legitimación" (p. 56). Pero los hechos no fueron estos, dice Pérez Vejo, sino estos otros: ninguno de los bandos contendientes consideraba extranjero al rey, como se sigue del hecho de los vivas a Fernando VII contenidos en la mayoría de las supuestas proclamas de independencia; los 
ejércitos de ambos bandos, realista e insurgente, se componían de americanos en su inmensa mayoría, tanto en la tropa como en la oficialidad; tras la derrota de Trafalgar ante los ingleses en 1805, así como las sufridas en toda la península ante los franceses en 1809, el pretendido ejército extranjero no podía trasladar tropas al otro lado del Atlántico, de manera que aquellas guerras no tuvieron prácticamente intervención externa, fuera de contadas excepciones; a consecuencia de ello, muchos de los realistas derrotados se incorporaron la vida política y militar de las nuevas naciones sin ser considerados extranjeros (cf. p. 58).

El iter de los hechos en aquellas guerras civiles fue más o menos el siguiente. Las abdicaciones de Bayona generaron una situación de inestabilidad política generalizada y las élites de la Monarquía se vieron obligadas a moverse en una situación anómala y excepcional, caracterizada por la ausencia del rey y la usurpación francesa del trono. "Los complejos equilibrios entre los funcionarios de la Corona, los funcionarios de la Iglesia y los de las élites locales se volvieron cada vez más inestables. Conforme la crisis se fue agravando, entre 1809 y 1810 , la situación de las autoridades reales se hizo cada vez más difícil, su legitimidad fue puesta en cuestión de forma cada vez más clara y, finalmente, el enfrentamiento entre los diferentes grupos llevó a una guerra civil generalizada en el conjunto de los territorios de la Monarquía" (p. 83). De esta situación de crisis y de revolución surgieron en todo el espacio de la Monarquía católica nuevas soberanías nacionales que ponían fin al Antiguo Régimen. "Esta revolución no concluiría en la década de los años veinte, sino bien entrado el siglo XIX. No se desmantela todo un sistema social y político de un día para otro y por decreto, en especial si [...] posiblemente no estamos tanto frente al fin de una forma de organización social y política como ante la desaparición de una forma de civilización" (p. 84). Así es como una larga guerra civil se desencadenó en todos los territorios de la América hispánica desde 1810 hasta algún momento, difícil de determinar, de la segunda mitad del siglo XIX, guerra civil que solo concluiría con el establecimiento de un nuevo sistema de legitimidad política, es decir, con la invención de naciones capaces de ocupar el lugar del rey en el imaginario político y de sustituir las corporaciones y los privilegios colectivos del Antiguo Régimen por una legitimidad nacional y una organización social basada en el individuo y sus derechos (cf. p. 87).

Desde luego, es claro que en el origen de esta larga guerra civil está "la desaparición por implosión de un sistema imperial fracasado, el de la Monarquía católica, y su sustitución por casi dos decenas de naciones nuevas" (p. 88). Jaime E. Rodríguez ha dicho que "cuando la gran comunidad hispánica, una confederación heterogénea como era la monarquía española, se quiebra, emergen nuevas naciones, entre ellas España” (p. 88). Ahora bien, y esto es un hecho clave en la reinterpretación de Pérez Vejo, la disgregación 
territorial resultante de tal quiebra no se produce por la pulsión y la voluntad de independencia de naciones preexistentes, sino porque nadie logra hacerse reconocer como el heredero legítimo de la anterior soberanía política encarnada por el rey (cf. p. 90).

Esta tesis, por otro lado, tiene la ventaja de explicar no sólo lo ocurrido en el proceso de las declaraciones de independencia entre 1810 y 1820, sino de ofrecer también la clave interpretativa de la larga inestabilidad política instaurada en todos los territorios de la Monarquía católica tras las décadas siguientes a las respectivas declaraciones de independencia. Pérez Vejo cita en tal sentido a Antonio Annino: "Cuando un imperio colapsa nadie es el heredero legítimo de la soberanía de la corona, ni siquiera las nuevas instituciones representativas que se apegan al principio de la nacionalidad. La acefalia del todo se extiende entonces hasta la última parte que se emancipa, dejando luego en herencia un serio problema de gobernabilidad" (p. 93).

Pérez Vejo no deja de indicar que esta interpretación de las guerras de independencia americanas como una guerra civil, si bien minoritaria hasta la década de 1980, ha sido sostenida desde los inicios del siglo XIX por diversos autores. "En las primeras décadas del siglo XIX no fueron pocos los políticos y escritores americanos que se refirieron a ellas como guerras civiles" (p. 85). Así lo hacía en México José María Tornel, que había tomado parte en aquellas guerras, al referirse a los excesos ocurridos en las guerras de México entre 1810 y 1821, "porque son inevitables en las guerras civiles" (p. 85). En pleno centenario de exaltación de las nuevas naciones, hacia 1910, no faltaron voces que cuestionaron el carácter independentista de aquellas guerras. Es el caso del venezolano Laureano Valellina, quien afirmaba que la llamada guerra de independencia venezolana había sido en realidad una guerra civil (cf. p. 86). En 1960 el historiador argentino Enrique Gandía, aunque limitándose prácticamente a la América del Sur, afirmaba que "en el origen de las independencias no hubo ni una revolución ni una lucha por la independencia, sino un conflicto por la soberanía, a partir de la crisis dinástica generada por los sucesos de Madrid, que desembocaría en una guerra civil y después en una guerra de independencia”. Finalmente, a partir de 1980 no pocos historiadores han puesto en cuestión de forma sistemática la imagen de las llamadas guerras de independencia como guerras de liberación nacional, dando comienzo así a una historiografía revisionista que exige un nuevo marco teórico general capaz de explicar mejor el proceso del fin del Antiguo Régimen en los territorios de la que fue la Monarquía católica (cf. p. 87).

$* * *$ 
Nos encontramos, pues, ante un valioso libro, referencia necesaria en el estudio del fenómeno de las llamadas guerras de la independencia hispanoamericanas, que a doscientos años de distancia de las mismas, con una laudable independencia de criterio y animado de un espíritu crítico y audaz a la vez, propone un nuevo paradigma explicativo de unos hechos, las guerras de independencia hispanoamericanas en efecto, que la historiografía dominante ha presentado (y re-presentado o imaginado) de un modo que su autor cree incongruente con hechos históricos bien establecidos. Desde luego, en materia de historia, como en toda otra ciencia, se ha de recurrir al fundamental principio epistemológico: contra facta non sunt argumenta. 